\title{
Porcelana colorida translúcida para luminárias decorativas
}

\section{(Translucent colored porcelain for decorative lighting fixtures)}

\author{
A. B. Jermolovicius ${ }^{1}$, A. L. Molisani ${ }^{1 *}$ \\ ${ }^{1}$ Centro Universitário Fundação Santo André, Faculdade de Engenharia "Celso Daniel" \\ Av. Ppe. de Gales 821, 09060-650, Santo André, SP, Brasil
}

\begin{abstract}
Resumo
Porcelanas translúcidas tradicionais são usuais para a produção de louça de mesa. Recentemente, identificou-se uma tendência moderna para utilizar a porcelana translúcida na produção de luxuosos artefatos de decoração, tais como luminárias para decoração de ambientes. Neste trabalho, desenvolveu-se uma formulação cerâmica para obter uma porcelana colorida e translúcida, cujo objetivo foi a obtenção de peças coloridas sem a necessidade de aplicação de vidrado colorido. Protótipos de luminária para decoração de ambiente foram produzidos, usando uma massa cerâmica triaxial (caulim, quartzo e feldspato) com adição de bentonita e wollastonita. O óxido de cobre preto $(\mathrm{CuO})$ foi usado como pigmento para colorir a massa cerâmica usada na produção da porcelana translúcida. $\mathrm{O}$ teor otimizado de $\mathrm{CuO}$ foi de $0,5 \%$ em massa, que resultou em uma porcelana translúcida de cor verde após sinterização ao ar a $1250{ }^{\circ} \mathrm{C}$ por $1 \mathrm{~h}$. A porcelana colorida e translúcida propiciou um efeito decorativo diferenciado em relação à porcelana translúcida tradicional sem adição de pigmentos.

Palavras-chave: porcelana, translúcida, transmitância, decoração.
\end{abstract}

\begin{abstract}
Traditional translucent porcelains are commonly used to produce tableware. Recently, a modern tendency has been identified to use translucent porcelain in the production of luxurious decorative artifacts, such as luminaires for the environment decoration. In this paper, a ceramic formulation was developed to obtain a colored and translucent porcelain, whose objective was obtaining colored pieces without the colored glaze application. Luminaire prototypes for environment decoration were produced using a triaxial ceramic mass (kaolin, quartz and feldspar) with the addition of bentonite and wollastonite. Black copper oxide (CuO) was used as a pigment to coloring the ceramic mass used for the translucent porcelain production. The optimum CuO content was $0.5 \mathrm{wt} \%$, which resulted in a translucent green porcelain after sintering in air at $1250{ }^{\circ} \mathrm{C}$ for $1 \mathrm{~h}$. The translucent colored porcelain provided a distinctive decorative effect compared to the traditional translucent porcelain without the addition of pigments.
\end{abstract}

Keywords: porcelain, translucent, transmittance, decoration.

\section{INTRODUÇÃO}

A porcelana usualmente é preparada com uma massa cerâmica denominada triaxial, porque é composta basicamente por argila, feldspato e quartzo [1]. A matéria-prima argila é usualmente o caulim, mas pode ser usada uma mistura de caulim e argila do tipo ball clay $[2,3]$. Há poucas diferenças entre o caulim e a argila ball clay, pois os dois argilominerais exibem uma natureza caulinítica e possuem quartzo $\left(\mathrm{SiO}_{2}\right)$ e ferro $\left(\mathrm{Fe}_{2} \mathrm{O}_{3}\right)$ como impurezas majoritárias e minoritárias, respectivamente [1]. As porcelanas exibem diversas aplicações, pois suas características físicas, químicas e mecânicas variam em função da composição química. A Fig. 1 mostra uma ilustração esquemática de um diagrama de fase ternário do sistema caulim-quartzo-feldspato, onde são mostradas várias aplicações para a porcelana em função de sua composição química triaxial.

A temperatura de sinterização (queima) da porcelana

*andre.molisani@fsa.br varia em função de sua composição química de 1200 a $1400{ }^{\circ} \mathrm{C}[2,4,5]$. As cerâmicas de mesa (whiteware ceramics) podem ser definidas como produtos altamente densos, contendo ou não camada de vidrado, comumente brancas, translúcidas e de textura fina [1,5]. Dentre as cerâmicas de mesa de alta qualidade, que podem apresentar translucidez, destacam-se a porcelana dura (hard porcelain) e a porcelana de osso (china bone), pois são produzidas em larga escala e dominam o mercado de louças de mesa [5,6]. A porcelana dura é composta por $50 \%$ de caulim, $25 \%$ de quartzo e $25 \%$ de feldspato, enquanto a porcelana de osso é constituída basicamente por $50 \%$ de osso animal calcinado, $25 \%$ de caulim e $25 \%$ de feldspato [5]. Porém, a composição típica de uma porcelana moderna de osso é dada por $50 \%$ de cinzas ósseas, $25 \%$ de feldspato e $25 \%$ de argila, sendo este último componente o caulim ou a mistura de caulim e argila ball clay [3]. Após conformação da peça, a porcelana dura é queimada incialmente ao redor de $1000{ }^{\circ} \mathrm{C}$ (obtenção do biscoito) e, então, aplica-se o vidrado com posterior queima em alta temperatura $\left(\sim 1400{ }^{\circ} \mathrm{C}\right)$ em uma atmosfera redutora 


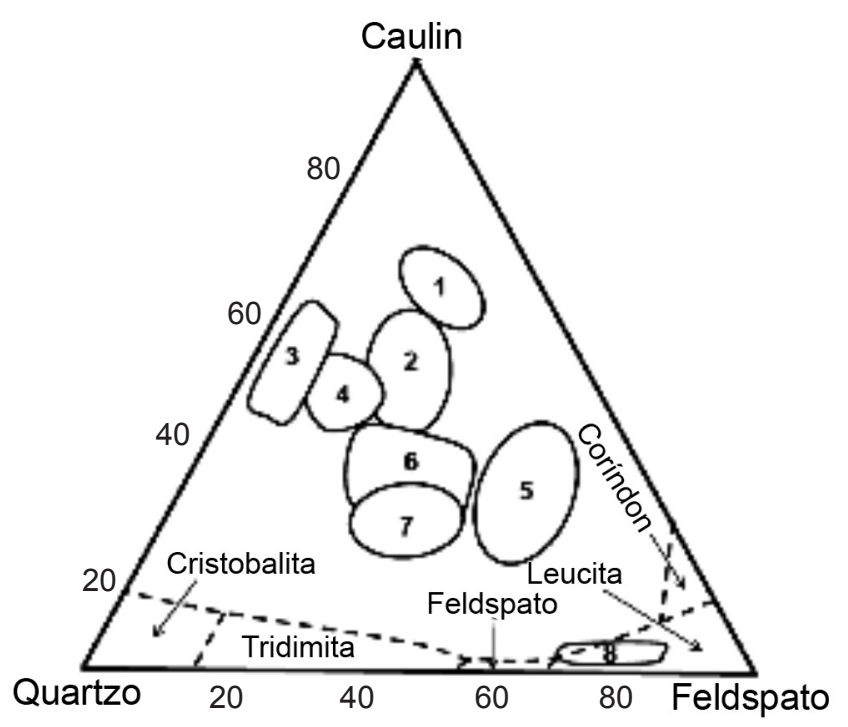

Figura 1: Ilustração esquemática de um diagrama fase ternário do sistema caulim-quartzo-feldspato, mostrando as áreas de aplicação típica para a porcelana em função de sua composição química triaxial: 1) porcelanas de laboratório; 2) porcelana dura; 3) louça de barro; 4) louça de barro vidrada; 5) grés porcelânico; 6) porcelana macia; 7) grés branco; e 8) porcelana dentária. Adaptado de [2].

[Figure 1: Schematic ternary phase diagram of the kaolin-quartzfeldspar system, showing the typical application areas for porcelain as a function of its triaxial chemical composition: 1) laboratory porcelain; 2) hard porcelain; 3) earthenware; 4) stoneware; 5) porcelain stoneware; 6) soft porcelain; 7) white stoneware; and 8) dental porcelain. Adapted from [2].]

[5]. Os contaminantes presentes nas matérias-primas (por ex. $\mathrm{Fe}_{2} \mathrm{O}_{3}$ e $\mathrm{TiO}_{2}$ ) são reduzidos durante a sinterização sob atmosfera redutora, o que leva à formação de compostos incolores, que afetam pouco a tonalidade da porcelana [7, 8]. A porcelana de osso também é submetida ao processo de biqueima. Neste caso, a primeira queima ocorre ao redor de $1230{ }^{\circ} \mathrm{C}$, seguida pela aplicação do vidrado e posterior queima entre 1050 e $1100{ }^{\circ} \mathrm{C}$ [5].

A densificação da porcelana ocorre pelo mecanismo de sinterização por fluxo viscoso, o que resulta em uma microestrutura caracterizada por uma matriz de fase vítrea $[1,2]$. Fases cristalinas, como quartzo e mulita, podem estar dispersas nesta matriz de fase vítrea [2, 9]. A porcelana dura tem uma microestrutura altamente vítrea $(70 \%$ de fase vítrea e $30 \%$ de fases cristalinas) [6], o que favorece a eliminação da porosidade [1]. No entanto, a elevada fração de fase vítrea afeta as características geométricas do produto cerâmico, bem como suas propriedades funcionais [2]. A microestrutura da porcelana de osso é composta por $70 \%$ de fases cristalinas e $30 \%$ de fase vítrea, o que confere altos valores de resistência mecânica, tenacidade à fratura e resistência ao lascamento de borda (resistance to edge chipping) em relação à porcelana dura [6]. A fase vítrea presente na microestrutura da porcelana tem uma natureza uniforme e estável, o que reduz a perda (absorção) de luz emergente, aumentando a transmitância de luz [10]. Outros fatores que afetam a transmitância nas porcelanas são: porosidade, impureza, contorno de grão, teor e tipo de aditivo, espessura do produto e os parâmetros de sinterização (temperatura, taxa de aquecimento e resfriamento, e atmosfera) [10]. A transmitância é significativamente influenciada pela presença de contornos de grão, principalmente em materiais anisotrópicos, pois a luz que passa pelo material é afetada (desviada) devido à presença de grãos com diferentes orientações cristalográficas [11]. Outro fator que diferencia a porcelana dura da porcelana de osso é a característica do vidrado. A porcelana dura tem um vidrado rico em sílica, que confere excelente resistência à abrasão e alta durabilidade química [5, 6]. Já o vidrado da porcelana de osso é facilmente riscado devido ao seu elevado teor de compostos alcalinos [5,6].

O processamento de louças de mesa translúcidas está estabelecido. Porém, verificou-se uma tendência moderna para utilizar a porcelana translúcida na produção de luxuosos artefatos de decoração, em especial luminárias para decoração de ambientes. Liu et al. [10] reportaram que tradicionalmente os objetos de decoração com efeito translúcido são obtidos por meio do uso de pedras naturais (por ex. mármore, cristais de rocha, ágata amarela, etc.), que necessitam de tecnologia avançada de processamento, o que aumenta significativamente os custos. Outra possibilidade é a produção destes objetos decorativos com produtos artificiais, que são compostos de resina, pós de pedra translúcidos e pigmentos translúcidos de coloração clara. O material artificial tem um preço acessível, mas deteriora rapidamente, perdendo seu aspecto decorativo. Uma alternativa é o uso de porcelana translúcida com composição química rica em sílica [10]. Este material possibilita a produção de peças duráveis, de boa qualidade e de preço acessível, mas o produto cerâmico exibe apenas a cor branca, necessitando aplicação de vidrado cerâmico para adquirir diferentes tonalidades. Além disso, materiais cerâmicos ricos em sílica apresentam um processamento criterioso devido à natureza polimórfica da sílica $[10$, 11]. No presente trabalho, pretende-se aperfeiçoar uma rota de processamento para produzir uma porcelana colorida e translúcida. Diferentes pigmentos (corantes) foram adicionados na massa cerâmica, objetivando-se a obtenção de peças de porcelana colorida e translúcida sem a necessidade de aplicação de vidrados coloridos. Além disso, pretende-se investigar o efeito da evolução microestrutural na translucidez das porcelanas sem e com pigmentação.

\section{MATERIAIS E MÉTODOS}

As matérias-primas foram adquiridas das empresas Minasolo Minérios e Grãos Abrasivos e Colorobbia Brasil. A Tabela I mostra a composição química das matériasprimas usadas na preparação das porcelanas. As porcelanas coloridas foram preparadas com os seguintes pigmentos comerciais da Colorobbia: azul C106 (composto por CoO, $\mathrm{ZnO}$ e $\mathrm{Al}_{2} \mathrm{O}_{3}$ ), verde $\mathrm{C} 73$ (composto por $\mathrm{Cr}_{2} \mathrm{O}_{3}$ e $\mathrm{SiO}_{2}$ ) e marrom $\mathrm{C} 103$ (composto por $\mathrm{Fe}_{2} \mathrm{O}_{3}, \mathrm{Cr}_{2} \mathrm{O}_{3}, \mathrm{Al}_{2} \mathrm{O}_{3}$ e NiO). Adicionalmente, os óxidos de cobre preto $(\geq 99 \% \mathrm{CuO})$ e de ferro vermelho (89-92\% $\mathrm{Fe}_{2} \mathrm{O}_{3}$ ) da Minasolo foram usados 
Tabela I - Composição química (\% em massa) das matérias-primas usadas na preparação das porcelanas. [Table I - Chemical composition (wt\%) of raw materials used in porcelain preparation.]

\begin{tabular}{ccccccc}
\hline Óxido & Caulim & Quartzo & $\begin{array}{c}\text { Feldspato } \\
\text { potássico }\end{array}$ & $\begin{array}{c}\text { Argila São } \\
\text { Simão }\end{array}$ & Bentonita & Wollastonita \\
\hline $\mathrm{SiO}_{2}$ & $45,2-46,0$ & 99,8 & 66,4 & 51,3 & 63 & $\leq 52,0$ \\
$\mathrm{Al}_{2} \mathrm{O}_{3}$ & $38,8-39,6$ & 0,15 & 18,2 & 31,8 & 21 & 0,4 \\
$\mathrm{Fe}_{2} \mathrm{O}_{3}$ & $0,08-0,45$ & 0,02 & 0,05 & 1,12 & $3-4$ & $\leq 2,0$ \\
$\mathrm{~K}_{2} \mathrm{O}$ & $0,2-0,3$ & - & 11,2 & 0,50 & $<1$ & - \\
$\mathrm{MgO}$ & $\leq 0,1$ & - & - & 0,20 & - & 0,3 \\
$\mathrm{Na}_{2} \mathrm{O}$ & $0,05-0,2$ & - & 3,6 & 0,02 & $2-3$ & - \\
$\mathrm{TiO}_{2}$ & TraçO & - & - & 1,04 & $<1$ & - \\
$\mathrm{CaO}$ & Isento & 0,01 & - & 0,25 & $<1$ & $\geq 44,0$ \\
$\mathrm{ZrO}$ & - & - & - & 0,03 & - & - \\
$\mathrm{P}_{2} \mathrm{O}_{5}$ & - & - & - & 0,07 & - & - \\
$\mathrm{BaO}^{\mathrm{BaO}}$ & - & - & - & 0,03 & - & - \\
$\mathrm{Perda}$ ao fogo & 14,0 & 0,14 & 0,4 & 13,6 & 8,0 & 1,98 \\
\hline
\end{tabular}

como pigmentos. As porcelanas preparadas com $\mathrm{CuO}$ e $\mathrm{Fe}_{2} \mathrm{O}_{3}$ exibiram as cores verde e cinza, respectivamente.

Jermolovicius et al. [12] desenvolveram uma formulação de massa cerâmica, sem pigmentação, para obter uma porcelana com adequada translucidez. Nesta etapa inicial, testaram-se 37 formulações cerâmicas, sendo analisada a translucidez apenas nas porcelanas sinterizadas a $1270{ }^{\circ} \mathrm{C}$ por $1 \mathrm{~h}$. A Tabela II mostra a composição química das 9 formulações cerâmicas que resultaram em porcelanas com significativa translucidez. A formulação F9 foi escolhida para o desenvolvimento da porcelana translúcida e colorida, pois exibiu o maior valor de transmitância após queima a $1270{ }^{\circ} \mathrm{C}$. Os resultados de transmitância das formulações F1 a F9 são apresentados na próxima seção. Além dos componentes da massa triaxial (caulim, quartzo e feldspato), adicionaram-se outros componentes, tais como: i) argila comercial São Simão, que é uma argila do tipo ball clay e, portanto, pode ser usada para substituir parcialmente o caulim na preparação de porcelanas translúcidas; ii) wollastonita para melhorar a compactação, reduzir retrações de secagem e sinterização e acelerar o processo de sinterização; e iii) bentonita para melhorar o processo de conformação da peça cerâmica - aumenta a resistência à verde.

A segunda etapa do trabalho consistiu em obter um pigmento (corante) para modificar a cor da porcelana sem causar significativas alterações na translucidez da porcelana preparada com a formulação F9 (Tabela II). Este estudo teve início em [12]. Neste caso, os diferentes pigmentos, cujos teores variaram de $0,02 \%$ a $1,5 \%$ em massa, foram adicionados diretamente na massa cerâmica. As matériasprimas foram peneiradas em malha ABNT 325 e, então, preparou-se $1 \mathrm{~kg}$ de massa cerâmica para cada uma das formulações F9 com diferentes teores de pigmento. A terceira e última etapa do trabalho consistiu na realização de melhorias no processamento cerâmico das porcelanas, tais como: obtenção de barbotinas estáveis, adequação do tipo e teor de pigmento e otimização da temperatura de sinterização para atingir máxima transmitância nas porcelanas sem e com pigmentação. Além disso, analisou-

Tabela II - Composição química (\% em massa) das formulações cerâmicas que resultaram em adequada transmitância [12].

[Table II - Chemical composition (wt\%) of the ceramic formulations that resulted in adequate transmittance [12].]

\begin{tabular}{cccccccccc}
\hline Matéria-prima & F1 & F2 & F3 & F4 & F5 & F6 & F7 & F8 & F9 \\
\hline Caulim & 45 & 25 & 50 & 53 & 44 & 48 & 54 & 43 & 43 \\
Feldspato potássico & 22 & 25 & 15 & 25 & 31 & 30 & 27 & 38 & 36 \\
Quartzo & 17 & 17 & 25 & 17 & 26 & 17 & 17 & 17 & 17 \\
Argila São Simão & 8 & 8 & - & 5 & 5 & 5 & - & - & - \\
Bentonita & - & - & - & - & - & - & 2 & 2 & 1 \\
Wollastonita & 8 & 15 & 10 & - & - & - & - & - & 3 \\
\hline
\end{tabular}

Nota: a formulação F9 foi escolhida para o desenvolvimento da porcelana colorida e translúcida. 
se o efeito da evolução microestrutural na transmitância das porcelanas sem e com pigmentação. Nesta última etapa, a mistura de pós cerâmicos foi homogeneizada a seco em moinho de bolas por $1 \mathrm{~h}$. Após estudo reológico da barbotina, estabeleceu-se uma quantidade de $0,18 \%$ em massa de dispersante $(2 \mathrm{~mL}$ de silicato de sódio com densidade de $1,4 \mathrm{~g} / \mathrm{cm}^{3}$ ) para uma suspensão contendo ao redor de 64\% em massa de sólidos (1 $\mathrm{kg}$ da mistura de pós cerâmicos) e ao redor de $36 \%$ em massa de líquido $(0,56 \mathrm{~kg}$ de água destilada). A peça cerâmica foi conformada pelo processo de colagem (slip casting) e sinterizada em forno elétrico (Jung) em diferentes temperaturas $\left(900\right.$ a $1270{ }^{\circ} \mathrm{C}$ ) por $1 \mathrm{~h}$, usando taxa de aquecimento de $5^{\circ} \mathrm{C} /$ min e resfriamento ao ar no forno. Para cada temperatura de sinterização, prepararam-se três corpos de prova por colagem, na forma de pastilha com $35 \mathrm{~mm}$ de diâmetro e $5 \mathrm{~mm}$ de espessura (para medição da densidade e porosidade) e placa retangular de 40 x $20 \mathrm{~mm}$ com espessura de 1 a $1,3 \mathrm{~mm}$ (para medição da transmitância das porcelanas). Uma balança semianalítica foi usada para determinar a densidade aparente (Eq. A) e a porosidade aparente (Eq. B) com base na norma ASTM C 373-88 [13]:

$$
\begin{aligned}
& \mathrm{DA}=\frac{\mathrm{M}_{\mathrm{S}}}{\mathrm{M}_{\mathrm{U}}-\mathrm{M}_{\mathrm{I}}} \rho_{\mathrm{L}} \\
& \mathrm{PA}=\left[\frac{\mathrm{M}_{U}-\mathrm{M}_{\mathrm{S}}}{\mathrm{M}_{\mathrm{U}}-\mathrm{M}_{\mathrm{I}}}\right] 100
\end{aligned}
$$

onde, DA é a densidade aparente $\left(\mathrm{g} / \mathrm{cm}^{3}\right), \mathrm{M}_{\mathrm{S}}$ é a massa da amostra seca (g), $M_{U}$ é a massa da amostra úmida (g) após imersão em água à temperatura ambiente por um período de $24 \mathrm{~h}, \mathrm{M}_{\mathrm{I}}$ é a massa da amostra imersa em água $(\mathrm{g}), \rho_{\mathrm{L}}$ é a densidade da água na temperatura ambiente $\left(\sim 1 \mathrm{~g} / \mathrm{cm}^{3}\right)$ e PA é a porosidade aparente (\%).

O microscópio eletrônico de varredura (MEV, FEI Quanta 650F) acoplado com um espectrômetro de energia dispersiva (EDS) foi usado na análise microestrutural e microanálise química das superfícies de fratura das porcelanas. Utilizou-se uma imagem de MEV com ampliação de 200x para determinar o tamanho de poro nas porcelanas sem e com pigmentação sinterizadas nas temperaturas de 1200,1250 e $1270{ }^{\circ} \mathrm{C}$. As imagens de MEV foram editadas em um programa de edição de imagem para realçar (pintar) os poros existentes na microestrutura e, então, o tamanho de poro foi determinado usando um programa de análise de imagem (ImageJ). Cada imagem analisada apresentou uma quantidade de poros, que variou de 310 a 2500 em função do tipo de porcelana e da temperatura de sinterização. $\mathrm{O}$ tamanho de poro foi expresso em área $\left(\mu \mathrm{m}^{2}\right)$ devido à sua forma geométrica complexa. A determinação da transmitância foi realizada em um espectrofotômetro de fabricação própria, usando comprimentos de onda $(\lambda)$ na faixa do verde $(525 \mathrm{~nm})$, amarelo $(590 \mathrm{~nm})$ e vermelho $(624 \mathrm{~nm})$. O espectrofotômetro é mostrado na Fig. 2, o qual foi constituído basicamente por dois sistemas eletroeletrônicos: i) emissor de luz com diferentes comprimentos de onda; e ii) sensor fotoelétrico que mediu a intensidade da luz que transpassou o corpo de prova. Após selecionar um comprimento de onda para a luz, colocou-se no suporte o espécime de vidro incolor e transparente (amostra padrão) e, então, determinouse a intensidade de luz que o transpassou. Sem deligar o dispositivo, a amostra padrão de vidro foi substituída pela amostra de porcelana e, então, determinou-se a intensidade de luz que a transpassou. A transmitância foi determinada pela Eq. C [14] para as porcelanas sem e com pigmentação sinterizadas a 1200,1210,1230,1250 e $1270^{\circ} \mathrm{C}$. Devido à dificuldade de preparação de amostras com espessuras similares, a transmitância foi dividida pela espessura, sendo este resultado denominado de transmitância específica $(\mathrm{Te}, \% / \mathrm{mm})$. Este procedimento foi realizado para equalizar o efeito da espessura da amostra na transmitância.

$$
\mathrm{T}=\frac{\mathrm{P}}{\mathrm{P}_{0}} \times 100
$$

onde, $\mathrm{T}$ é a transmitância, $\mathrm{P}$ é a intensidade de luz que transpassa a porcelana e $\mathrm{P}_{0}$ é a intensidade de luz que transpassa a amostra de vidro incolor e transparente.

\section{RESULTADOS E DISCUSSÃO}

A primeira etapa do trabalho foi determinar uma

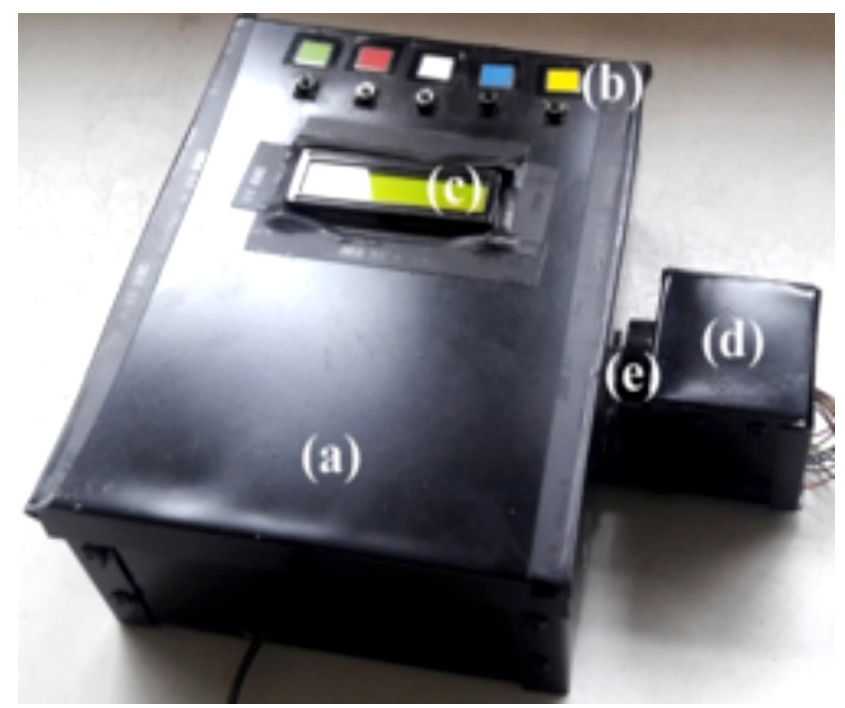

Figura 2: Imagem do protótipo de espectrofotômetro, que foi constituído por sistema de geração e emissão de luz (a), sistema de variação do comprimento de onda da luz emitida (b), visor digital que mostra o valor da intensidade de luz que transpassa a amostra (c), sensor fotoelétrico que mede a intensidade da luz que transpassa a amostra (d) e porta amostra (e).

[Figure 2: Image of a spectrophotometer prototype, which was constituted by light generation and emission system (a), variation system of emitted light wavelength (b), digital display that shows the value of the light intensity that passes through the specimen (c), photoelectric sensor that measures the light intensity that passes through the specimen $(d)$, and sample holder $(e)$. 
formulação cerâmica, sem adição de pigmento (ou corante), para ser usada como massa padrão para o desenvolvimento da porcelana translúcida e colorida. As composições químicas das porcelanas que exibiram boas características de translucidez são apresentadas na Tabela II. A Fig. 3 mostra os resultados de transmitância específica (Te) destas porcelanas, as quais foram sinterizadas ao ar na temperatura de $1270{ }^{\circ} \mathrm{C}$ por $1 \mathrm{~h}$. Apesar das formulações F3, F4, F6 e F7 terem exibido um aspecto visual de translucidez, as referidas porcelanas tiveram valores de $\mathrm{Te}=0$ para a luz verde $(\lambda=525$ $\mathrm{nm})$. As formulações F1, F2 e F8 tiveram valores próximos de Te para os três comprimentos de onda (Fig. 3), cujos valores variaram de 18 a $24 \% / \mathrm{mm}$ para a luz verde, 24 a $27 \% / \mathrm{mm}$ para a luz amarela $(\lambda=590 \mathrm{~nm})$ e 44 a $47 \% / \mathrm{mm}$ para a luz vermelha $(\lambda=624 \mathrm{~nm})$. O melhor resultado de transmitância foi obtido para a porcelana preparada com a formulação F9 (Tabela II), pois atingiu os seguintes valores de Te (Fig. 3): $\sim 30 \% / \mathrm{mm}$ em $\lambda=525 \mathrm{~nm}, \sim 44 \% / \mathrm{mm}$ em $\lambda=590 \mathrm{~nm}$ e $\sim 76 \% / \mathrm{mm}$ em $\lambda=624 \mathrm{~nm}$.

A segunda etapa do trabalho foi verificar o efeito do tipo e teor de pigmento (corante) na translucidez da porcelana preparada com a formulação F9. A Fig. 4 mostra a

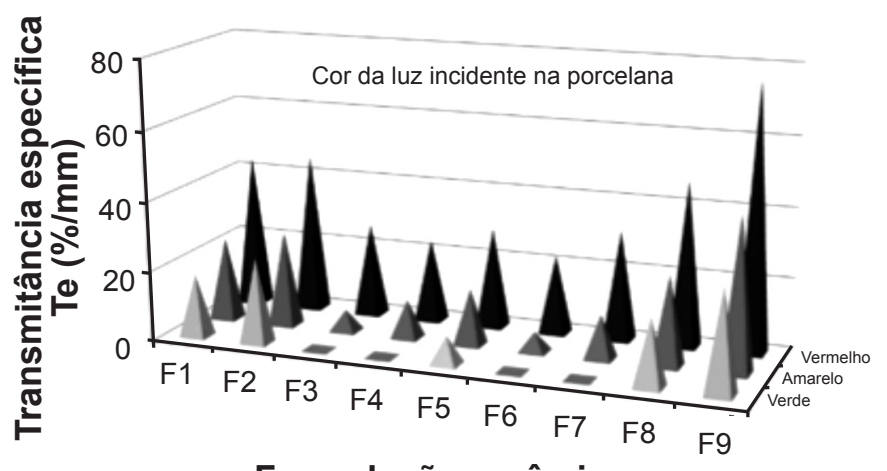

Formulação cerâmica

Figure 3: Transmitância específica de porcelanas preparadas com diferentes formulações cerâmicas e sinterizadas a $1270{ }^{\circ} \mathrm{C}$ [12].

[Figure 3: Specific transmittance of porcelain prepared with different ceramic formulations and sintered at $1270{ }^{\circ} \mathrm{C}$ [12].]

transmitância específica (Te) da porcelana sem e com adição de diferentes pigmentos. Todos os corantes, adiconados abaixo de 0,2\% em massa, não causaram alterações perceptíveis na tonalidade da porcelana e, portanto, não se determinou a transmitância nestas porcelanas. Os corantes comerciais azul C106 e marrom C103, quando adicionados na quantidade de $0,2 \%$ em massa, diminuíram significativamente a translucidez da porcelana (Fig. 4). Para o referido teor de pigmento, os dois corantes (C106 e C103) causaram mudanças quase imperceptíveis na tonalidade da porcelana. Já o corante verde C73 quase tornou a porcelana opaca para adições a partir de $0,2 \%$ em massa (Fig. 4), pois a porcelana apresentou apenas $\mathrm{Te} \sim 12 \% / \mathrm{mm}$ para a luz vermelha. Este corante também causou uma alteração quase imperceptível na tonalidade da porcelana quando adiconado na quantidade de $0,2 \%$ em massa. Os três pigmentos comerciais, quando adicionados na quantidade de $0,5 \%$ em massa, causaram alterações quase imperceptíveis na

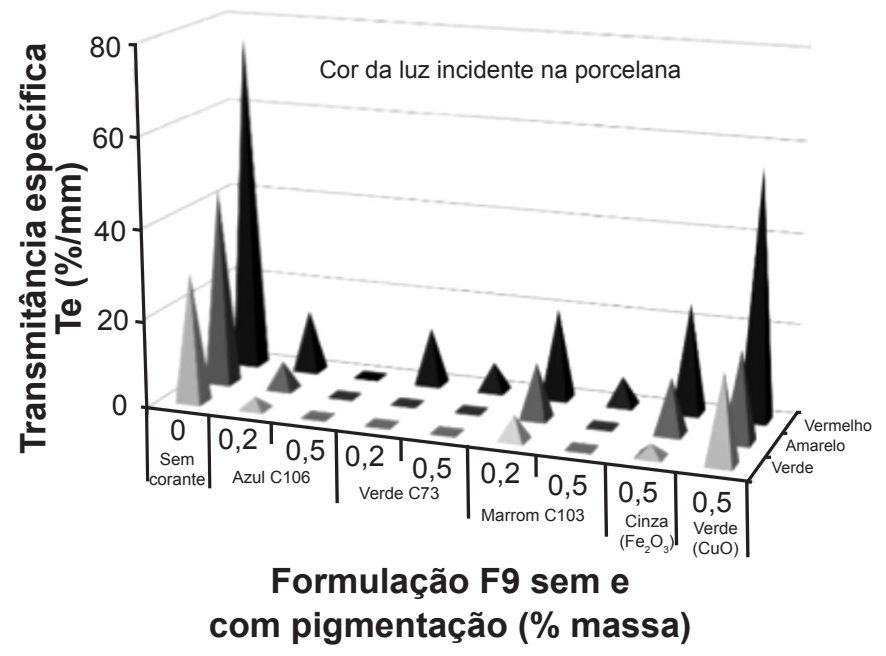

Figura 4: Transmitância específica da porcelana sem e com pigmentação sinterizada a $1270{ }^{\circ} \mathrm{C}[12]$.

[Figure 4: Specific transmittance of porcelain without and with pigmentation sintered at $1270{ }^{\circ} \mathrm{C}$ [12].]

tonalidade, mas este teor de pigmento foi o suficiente para tornar praticamente opaca a porcelana (Fig. 4). A adição de $0,5 \%$ em massa de óxido de ferro $\left(\mathrm{F}_{2} \mathrm{O}_{3}\right)$ mudou levemente a tonalidade da porcelana para cinza claro, cujos valores de Te foram relativamente próximos àqueles obtidos para a porcelana com $0,2 \%$ em massa de corante comercial marrom C103 (Fig. 4). O corante de óxido de cobre preto $(\mathrm{CuO})$ alterou a tonalidade da porcelana para verde claro, mas isso ocorreu somente para adições acima de 0,2\% em massa (Fig. 4). Para $0,5 \%$ em massa de $\mathrm{CuO}$, obtiveram-se os maiores valores de Te para as três cores de luz incidente na porcelana (Fig. 4). Os pigmentos intensificaram gradualmente a cor da porcelana para adições acima de 0,5\% em massa (Fig. 5), mas valores de $\mathrm{Te}=0$ foram obtidos, mostrando que a porcelana tornou-se opaca. Em suma, a porcelana com adição de $0,5 \%$ em massa de $\mathrm{CuO}$ atingiu a melhor condição de translucidez após sinterização a $1270{ }^{\circ} \mathrm{C}$ por $1 \mathrm{~h}$.

A terceira etapa do trabalho foi levantar a curva de densificação da porcelana sem pigmentação e com adição

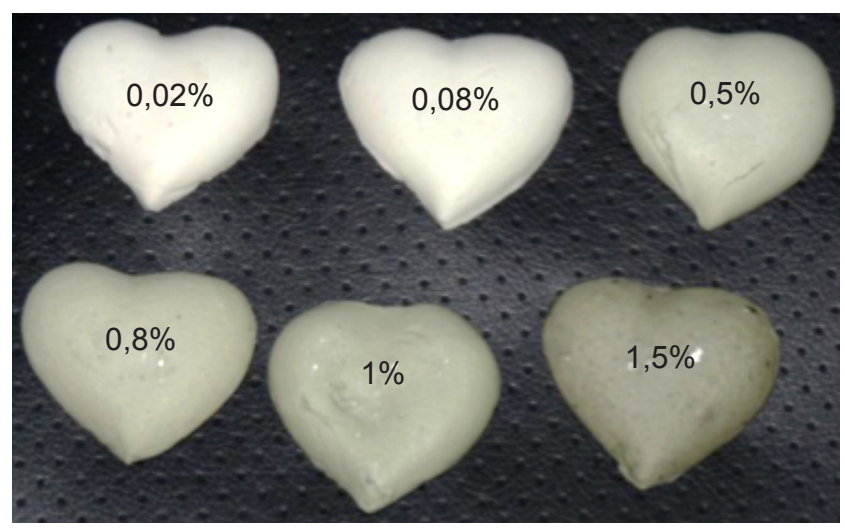

Figura 5: Imagem das porcelanas com diferentes teores de $\mathrm{CuO}(\%$ em massa) sinterizada a $1270{ }^{\circ} \mathrm{C}$ [12].

[Figure 5: Photograph of porcelains with different $\mathrm{CuO}$ contents (wt\%) sintered at $1270{ }^{\circ} \mathrm{C}$ [12].] 
de $0,5 \%$ em massa de $\mathrm{CuO}$ e, então, verificar o efeito da temperatura de sinterização na transmitância específica. A Fig. 6a mostra a densidade aparente (DA) em função da temperatura de sinterização das porcelanas sem pigmentação e com $0,5 \%$ de $\mathrm{CuO}$. As duas porcelanas tiveram valores próximos de DA após sinterização até $1000{ }^{\circ} \mathrm{C}$, indicando que a adição de $\mathrm{CuO}$ não influenciou a densificação em baixas temperaturas $\left(\leq 1000{ }^{\circ} \mathrm{C}\right)$. Porém, a porcelana com $\mathrm{CuO}$ teve rápida densificação em relação à porcelana sem pigmentação entre 1000 e $1100{ }^{\circ} \mathrm{C}$, indicando que a adição de $0,5 \%$ de $\mathrm{CuO}$ aumentou a taxa de densificação da porcelana. Após sinterização a $1150{ }^{\circ} \mathrm{C}$, as duas porcelanas exibiram valores próximos de DA, mostrando que a adição de $\mathrm{CuO}$ teve uma ação benéfica para a densificação somente nos estágios iniciais da sinterização. Na temperatura de $1150{ }^{\circ} \mathrm{C}$, a porcelana com $0,5 \%$ de $\mathrm{CuO}$ atingiu máximo valor de DA $\left(2,34 \mathrm{~g} / \mathrm{cm}^{3}\right.$, Fig. 6a) e, então, a DA começou a decair em função do aumento da temperatura de sinterização $\left(1,98 \mathrm{~g} / \mathrm{cm}^{3}\right.$ a $\left.1270{ }^{\circ} \mathrm{C}\right)$. O mesmo comportamento foi observado para a porcelana sem pigmentação. Porém, a porcelana sem pigmentação atingiu máximo valor de DA a $1200{ }^{\circ} \mathrm{C}\left(2,39 \mathrm{~g} / \mathrm{cm}^{3}\right)$ e teve um menor decaimento de DA em função do aumento da temperatura de sinterização $\left(2,17 \mathrm{~g} / \mathrm{cm}^{3}\right.$ a $\left.1270{ }^{\circ} \mathrm{C}\right)$.

A Fig. $6 \mathrm{~b}$ mostra a porosidade aparente (PA) em função da temperatura de sinterização para as porcelanas sem pigmentação e com adição de $0,5 \%$ em massa de $\mathrm{CuO}$. Os valores de PA das duas porcelanas diminuíram com o aumento da temperatura de sinterização, seguindo a mesma tendência do comportamento de DA (Fig. 6a). Como o ensaio de PA fornece o provável volume de poros abertos no corpo sinterizado, verificou-se que a porcelana com $0,5 \%$ de $\mathrm{CuO}$ não exibiu poros abertos a partir de $1150{ }^{\circ} \mathrm{C}$, pois sua PA foi próxima de zero a partir desta temperatura de sinterização (Fig. 6b). O mesmo ocorreu para a porcelana sem pigmentação, mas a PA foi próxima de zero a partir de $1200{ }^{\circ} \mathrm{C}$. O preenchimento dos poros abertos é associado à formação de fase líquida, que é decorrente da fusão de compostos do sistema $\mathrm{K}_{2} \mathrm{O}-\mathrm{SiO}_{2}-\mathrm{Al}_{2} \mathrm{O}_{3}$ a partir de $980{ }^{\circ} \mathrm{C}$ e da fusão do feldspato acima de $1100{ }^{\circ} \mathrm{C}$ [15]. A fração de fase líquida aumenta com o aumento da temperatura de sinterização, cuja temperatura de início da formação de fase líquida ocorre acima de $900{ }^{\circ} \mathrm{C}$ para cerâmicas tradicionais com massa triaxial [16]. Como a porcelana com $0,5 \%$ de $\mathrm{CuO}$ teve uma taxa de redução de PA maior do que a porcelana sem pigmentação acima de $1000{ }^{\circ} \mathrm{C}$, acredita-se que a adição de $\mathrm{CuO}$ diminuiu a viscosidade da fase líquida, o que favoreceu o preenchimento dos poros abertos em menores temperaturas de sinterização. Além disso, a adição de $\mathrm{CuO}$ pode aumentar a fração de fase líquida durante a sinterização, pois é prevista a formação de fase líquida a partir de $1090{ }^{\circ} \mathrm{C}$ para o sistema $\mathrm{Cu}_{2} \mathrm{O}-\mathrm{SiO}_{2}-\mathrm{Al}_{2} \mathrm{O}_{3}$ [17] ou a partir de $1150{ }^{\circ} \mathrm{C}$ para o sistema $\mathrm{Cu}-\mathrm{O}-\mathrm{Al}_{2} \mathrm{O}_{3}-\mathrm{SiO}_{2}$ [18]. Apesar dos poros abertos terem sido eliminados após sinterização entre 1150 e $1200{ }^{\circ} \mathrm{C}$ (Fig. 6b), os valores de DA diminuíram significativamente com o aumento da temperatura de sinterização para as duas porcelanas (Fig. 6a).
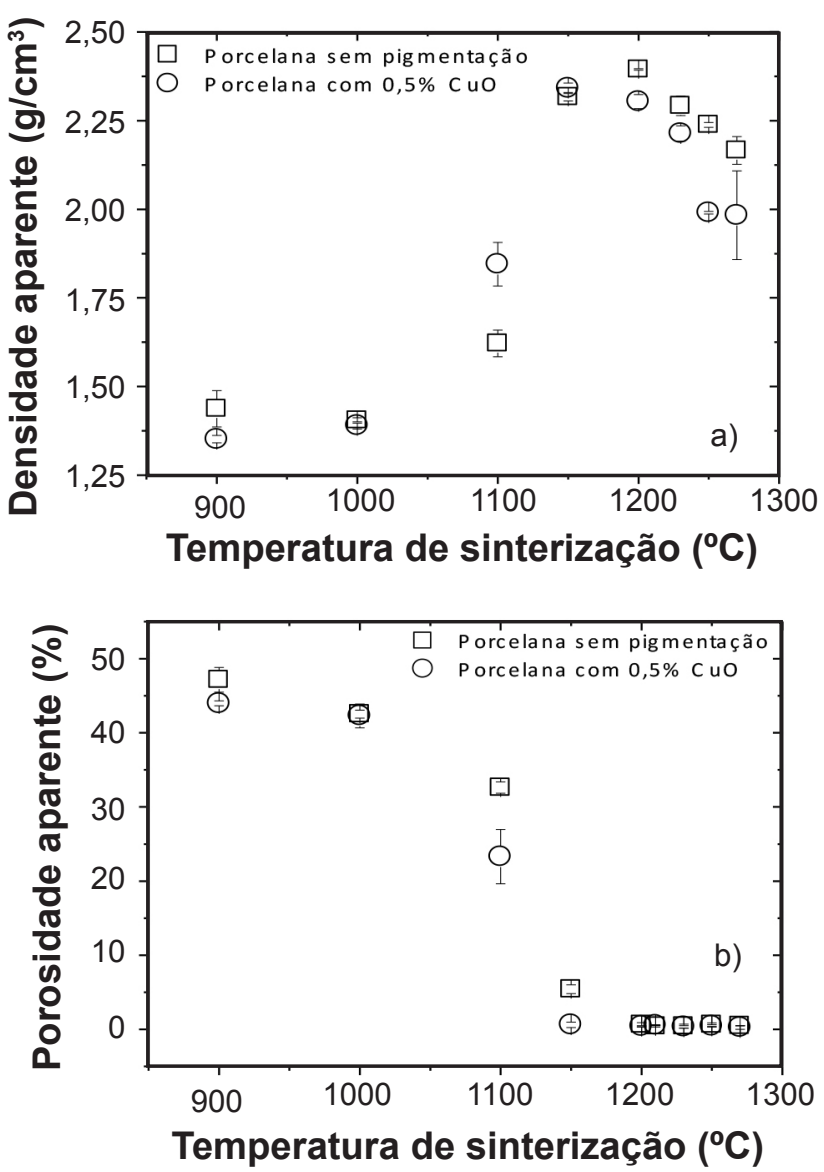

Figura 6: Densidade aparente, DA (a), e porosidade aparente, PA (b), das porcelanas sem e com adição de $0,5 \%$ em massa de $\mathrm{CuO}$ sinterizadas em diferentes temperaturas.

[Figure 6: Bulk density (a) and apparent porosity (b) of the porcelains without and with addition of $0.5 \mathrm{wt} \% \mathrm{CuO}$ sintered at different temperatures.]

Este decaimento de DA, bem como a PA tendendo a zero, é indicativo de que os poros fechados (existentes no interior do corpo cerâmico) coalesceram e/ou cresceram durante a sinterização em altas temperaturas $\left(>1150{ }^{\circ} \mathrm{C}\right)$. A utilização de temperatura de sinterização acima da necessária para atingir máxima densidade causa o inchamento (bloating) da peça cerâmica devido ao aumento da pressão de gás aprisionado no interior dos poros fechados, o que resulta em rápida diminuição de densidade [2,3].

A Fig. 7 mostra imagens de MEV das superfícies de fratura das porcelanas sem pigmentação e com $0,5 \% \mathrm{em}$ massa de $\mathrm{CuO}$ sinterizadas em diferentes temperaturas. A porcelana sem pigmentação sinterizada a $1200{ }^{\circ} \mathrm{C}$ exibiu uma microestrutura com matriz vítrea e elevada fração de pequenos poros, mas observaram-se alguns grandes poros esféricos ou grandes poros coalescidos (Fig. 7a). A fração de grandes poros aumentou na porcelana sem pigmentação, enquanto que a fração de pequenos poros diminuiu em função do aumento da temperatura de sinterização (Fig. 7b). A Fig. 8a mostra a distribuição de poros na porcelana sem pigmentação para diferentes temperaturas de sinterização. As curvas de distribuição de poros deslocaram para maiores 

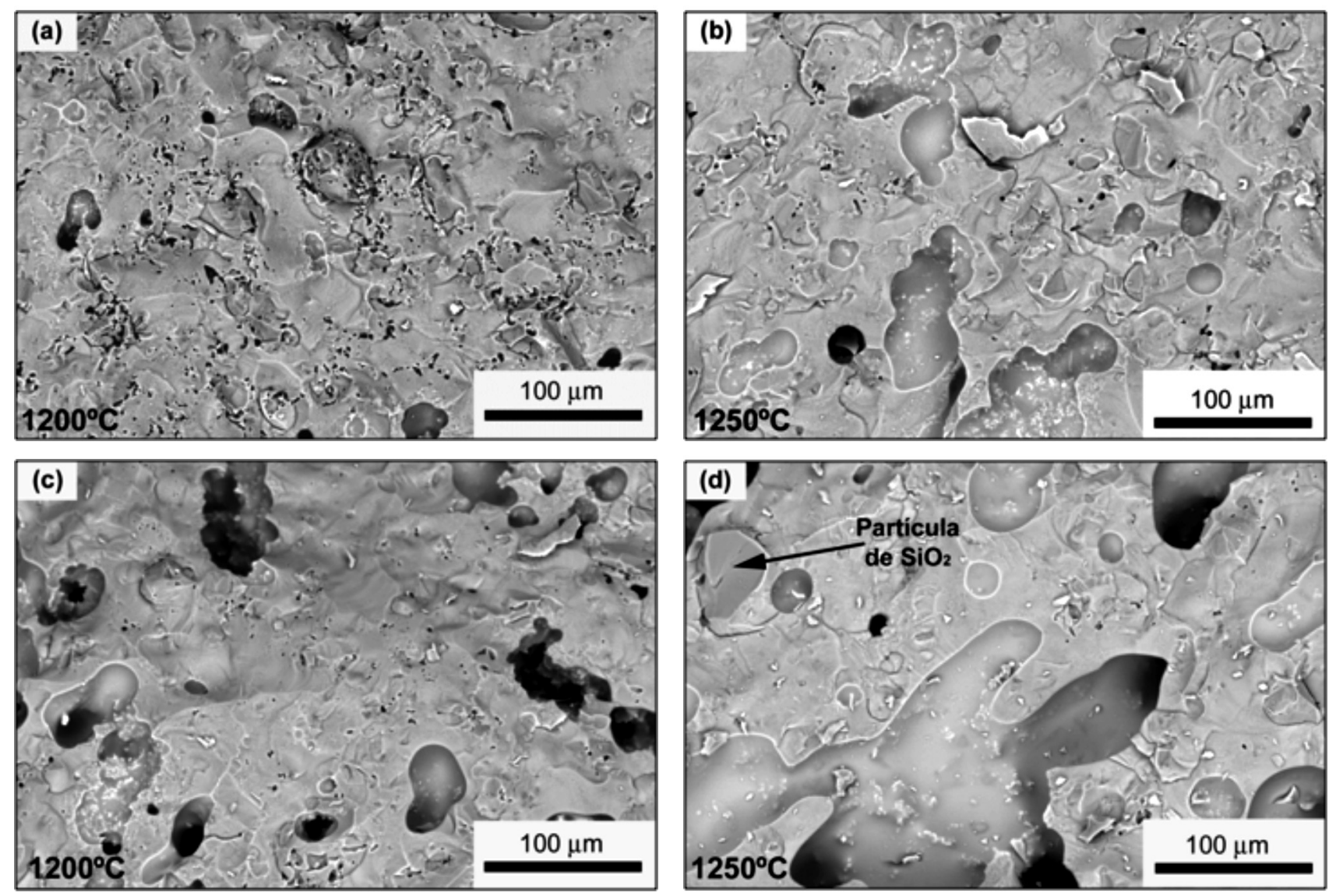

Figura 7: Imagens de elétrons secundários (MEV) das superfícies de fratura das porcelanas sem pigmentação (a, b) e com adição de 0,5\% em massa de $\mathrm{CuO}$ (c, d) sinterizadas em diferentes temperaturas.

[Figure 7: Secondary electron images (SEM) of fracture surfaces of porcelains without pigmentation $(a, b)$ and with addition of 0.5 wt\% $\mathrm{CuO}(c, d)$ sintered at different temperatures.]
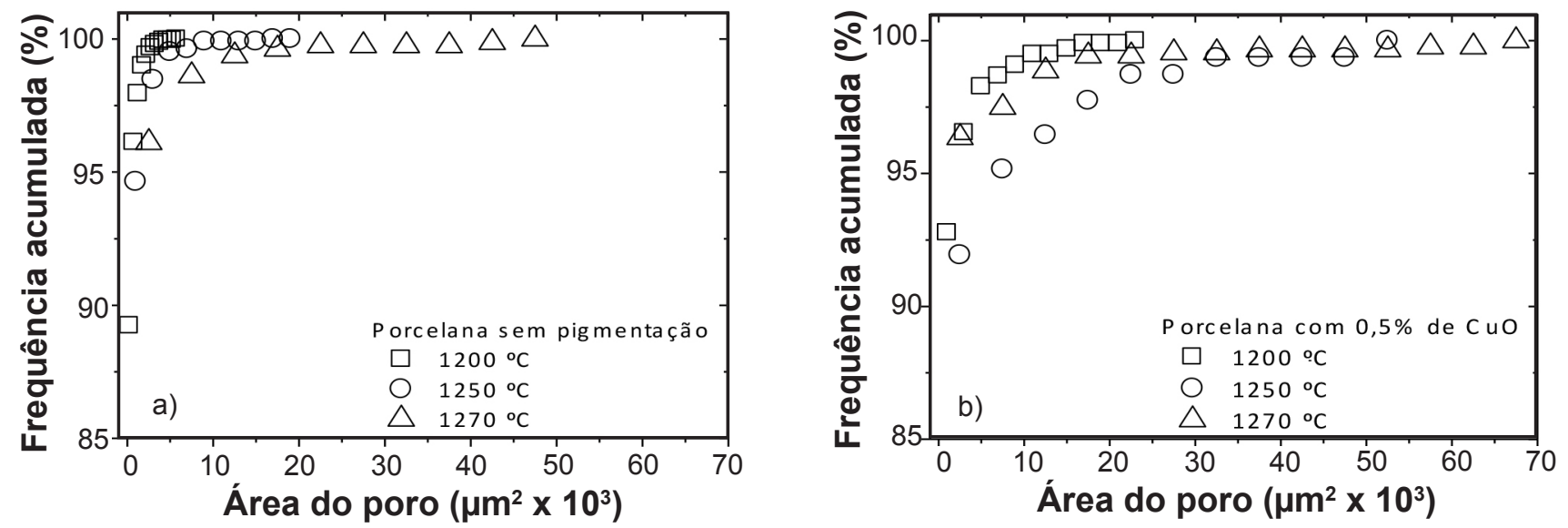

Figura 8: Fração em área de poros das porcelanas sem pigmentação (a) e com adição de 0,5\% em massa de CuO (b) sinterizadas em diferentes temperaturas.

[Figure 8: Pore area fraction of the porcelains without pigmentation (a) and with addition of 0.5 wt\% CuO (b) sintered at different temperatures.]

valores com o aumento da temperatura de sinterização, indicando que os poros aumentaram de tamanho em função do aumento de temperatura. A análise destas curvas de distribuição mostrou que os tamanhos médios e máximos dos poros aumentaram, mas o número de poros analisados na microestrutura diminuiu com o aumento da temperatura de sinterização (Tabela III). Esta diminuição na quantidade de poros mostrou que os poros coalesceram com o aumento da temperatura de sinterização. Neste caso, os poros pequenos foram 'consumidos' pelos poros grandes com o aumento da temperatura de sinterização, o que resultou em uma microestrutura com matriz vítrea densa e grandes 
Tabela III - Resultado da distribuição de área do poro das porcelanas sem e com 0,5\% em massa de CuO sinterizadas em diferentes temperaturas.

[Table III - Result of the pore area distribution of the porcelains without pigmentation and with addition of $0.5 \mathrm{wt} \% \mathrm{CuO}$ sintered at different temperatures.]

\begin{tabular}{ccccc}
\hline Porcelana & $\begin{array}{c}\text { Área média de } \\
\text { poro }\left(\mu \mathrm{m}^{2}\right)\end{array}$ & $\begin{array}{c}\text { Área mínima } \\
\text { de poro }\left(\mu \mathrm{m}^{2}\right)\end{array}$ & $\begin{array}{c}\text { Área máxima } \\
\text { de poro }\left(\mu \mathrm{m}^{2}\right)\end{array}$ & $\begin{array}{c}\text { Número de poros } \\
\text { analisados }\end{array}$ \\
\hline Sem pigmentação $-1200{ }^{\circ} \mathrm{C}$ & 222 & 2 & 5765 & 2500 \\
Sem pigmentação $-1250^{\circ} \mathrm{C}$ & 467 & 2 & 17884 & 1046 \\
Sem pigmentação $-1270{ }^{\circ} \mathrm{C}$ & 946 & 7 & 48489 & 798 \\
\hline $0,5 \%$ de $\mathrm{CuO}-1200{ }^{\circ} \mathrm{C}$ & 609 & 2 & 23446 & 982 \\
$0,5 \%$ de $\mathrm{CuO}-1250^{\circ} \mathrm{C}$ & 2111 & 2 & 53608 & 310 \\
$0,5 \%$ de $\mathrm{CuO}-1270{ }^{\circ} \mathrm{C}$ & 1018 & 2 & 69677 & 878 \\
\hline
\end{tabular}

poros dispersos (Fig. 7b). Apesar da obtenção de uma matriz vítrea densa acima de $1200^{\circ} \mathrm{C}$, a ocorrência de crescimento e coalescimento de poros causou uma diminuição significativa na densidade da porcelana sem pigmentação após sinterização em altas temperaturas $\left(>1200^{\circ} \mathrm{C}\right.$, Fig. 6a).

A $1200{ }^{\circ} \mathrm{C}$, a porcelana com $0,5 \%$ de $\mathrm{CuO}$ exibiu uma microestrutura com matriz vítrea densa (Fig. 7c), cuja quantidade de poros pequenos foi menor em relação à porcelana sem pigmentação (Fig. 7a). Por outro lado, a porcelana com $0,5 \%$ de $\mathrm{CuO}$ teve maior quantidade de poros grandes do que a porcelana sem pigmentação após sinterização a $1200{ }^{\circ} \mathrm{C}$. Os poros pequenos foram sendo eliminados da matriz vítrea da porcelana com $0,5 \%$ de $\mathrm{CuO}$ com o aumento da temperatura de sinterização (Figs. 7c e $7 \mathrm{~d}$ ), mas os poros grandes cresceram significativamente em comparação com a porcelana sem pigmentação (Figs. 7a e 7b). Este rápido crescimento dos poros grandes causou uma significativa redução na densidade da porcelana com 0,5\% de $\mathrm{CuO}$, cujo decaimento de densidade foi superior àquele observado para a porcelana sem pigmentação $(>1200$ ${ }^{\circ} \mathrm{C}$, Fig. 6a). A Fig. 8b mostra a distribuição de poros na porcelana com $0,5 \%$ de $\mathrm{CuO}$ para diferentes temperaturas de sinterização. Esta porcelana apresentou uma distribuição de poros que deslocou para maiores valores entre $1200 \mathrm{e}$ $1250{ }^{\circ} \mathrm{C}$ e, então, retornou para menores valores entre 1250 e $1270{ }^{\circ} \mathrm{C}$. O número de poros analisados diminuiu significativamente entre 1200 e $1250^{\circ} \mathrm{C}$ (Tabela III), mas os tamanhos médios e máximos dos poros aumentaram nesta faixa de temperatura. Portanto, os poros coalesceram entre 1200 e $1250{ }^{\circ} \mathrm{C}$, pois os poros menores foram consumidos pelos grandes poros, o que resultou em uma microestrutura com matriz vítrea densa e grandes poros dispersos (Figs. $7 \mathrm{c}$ e $7 \mathrm{~d}$ ). Entretanto, a porcelana com $0,5 \%$ de $\mathrm{CuO}$ teve um aumento significativo tanto no número de poros analisados como no tamanho máximo dos poros entre 1250 e $1270{ }^{\circ} \mathrm{C}$ (Tabela III), mas seu tamanho médio de poro diminuiu significativamente nesta faixa de temperatura de sinterização. Neste caso, o aumento do número de poros analisados indicou que o aumento da temperatura de sinterização, acima de $1250{ }^{\circ} \mathrm{C}$, intensificou a formação de poros. Além disso, o aumento do tamanho máximo dos poros indicou que os poros cresceram ou coalesceram entre $1250 \mathrm{e}$
$1270{ }^{\circ} \mathrm{C}$. Porém, a diminuição do tamanho médio dos poros indicou que parte dos poros, formados acima de $1250{ }^{\circ} \mathrm{C}$, não foi consumida pelos grandes poros, o que causou uma maior variação de tamanho dos poros na microestrutura. Deste modo, a curva de distribuição de poros da porcelana com $0,5 \%$ de $\mathrm{CuO}$ deslocou para menores valores entre 1250 e $1270{ }^{\circ} \mathrm{C}$ (Fig. 8b).

Conforme explanação anterior, sugeriu-se que a adição de $\mathrm{CuO}$ diminuiu a viscosidade da fase líquida, o que favoreceu o preenchimento dos poros abertos em menores temperaturas de sinterização. Porém, a diminuição de viscosidade da fase líquida pode levar à formação de poros durante os estágios iniciais da sinterização realizada acima da temperatura necessária para atingir máxima densificação [15]. Outro fator que pode contribuir para a formação de poros é a liberação de gases, tais como grupos $\mathrm{OH}$ e nitrogênio [15] ou oxigênio e nitrogênio [9] durante a sinterização de porcelanas tradicionais. Porém, para a porcelana com $\mathrm{CuO}$, acredita-se que compostos à base de cobre podem evaporar durante a sinterização acima de $1150{ }^{\circ} \mathrm{C}$, já que a região da fase líquida do sistema $\mathrm{Cu}_{2} \mathrm{O}-\mathrm{Al}_{2} \mathrm{O}_{3}-\mathrm{SiO}_{2}$ deve incluir o lado rico em $\mathrm{Cu}_{2} \mathrm{O}$ [19]. As microanálises químicas por EDS mostraram que as porcelanas sem pigmentação e com adição de $0,5 \%$ de $\mathrm{CuO}$ sinterizadas entre 1200 e $1270{ }^{\circ} \mathrm{C}$ tiveram matrizes vítreas (Fig. 7) compostas por $\mathrm{K}, \mathrm{O}, \mathrm{Na}, \mathrm{Al}, \mathrm{Si}$ e $\mathrm{Ca}$ (Fig. 9a), além de $\mathrm{Cu}$ identificado apenas na porcelana com pigmentação. Com base na composição das matériasprimas (Tabela II), verificou-se que a presença de $\mathrm{K}$ foi decorrente principalmente do uso de feldspato potássico, enquanto o $\mathrm{Na}$ foi oriundo de várias fontes (caulim, feldspato potássico e bentonita) e o Ca foi proveniente da wollastonita $\left(\mathrm{CaSiO}_{3}\right)$. Apesar dos compostos $\mathrm{Na}_{2} \mathrm{O}$ e $\mathrm{CaO}$ possuírem excelente habilidade para fundir o quartzo [10], partículas de $\mathrm{SiO}_{2}$ foram observadas dispersas na matriz vítrea das duas porcelanas sinterizadas até $1250{ }^{\circ} \mathrm{C}$ (Figs. $7 \mathrm{~d}$ e 9b). Porcelanas de mesa podem apresentar, além de fase vítrea, residuais de fases cristalinas como mulita $\left(3 \mathrm{Al}_{2} \mathrm{O}_{3} \cdot 2 \mathrm{SiO}_{2}\right)$, quartzo $\left(\mathrm{SiO}_{2}\right)$ e feldspato $\left(\mathrm{KAlSi}_{3} \mathrm{O}_{8}\right.$ ou NaAlSi$\left.{ }_{3} \mathrm{O}_{8}\right)$ [2]. Já a presença de cobre $(\mathrm{Cu})$ na porcelana com pigmentação indicou que sua fase vítrea teve compostos contendo cobre, o que pode resultar na diminuição da viscosidade da fase líquida e no aumento da evaporação de compostos durante 

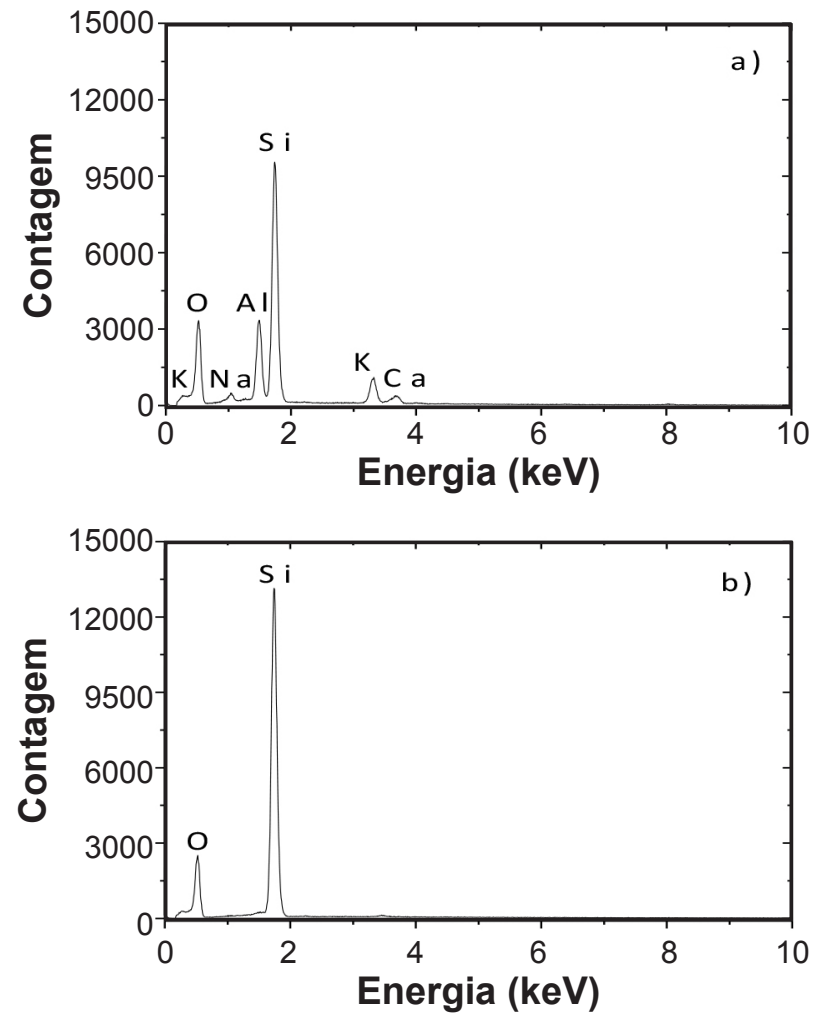

Figura 9: Espectros de EDS das superfícies de fratura da porcelana com 0,5\% em massa de $\mathrm{CuO}$ sinterizada a $1250{ }^{\circ} \mathrm{C}$ : (a) matriz vítrea; e (b) partícula de $\mathrm{SiO}_{2}$ dispersa na matriz vítrea (Fig. 7d).

[Figure 9: EDS spectra of the fracture surfaces of porcelain with the addition of $0.5 \mathrm{wt} \% \mathrm{CuO}$ sintered at $1250{ }^{\circ} \mathrm{C}:$ (a) glassy matrix; and (b) $\mathrm{SiO}_{2}$ particle dispersed in the glassy matrix (Fig. 7d).]

a sinterização. Portanto, a porcelana com $0,5 \%$ de $\mathrm{CuO}$ teve maior decaimento de densidade do que a porcelana sem pigmentação $\left(>1200{ }^{\circ} \mathrm{C}\right.$, Fig. 6a) devido à ocorrência dos fatores supracitados, visto que ambos contribuíram para a formação de poros em altas temperaturas de sinterização. Independente da adição de $\mathrm{CuO}$, o decaimento de densidade pode ser associado a outros fatores, tais como: i) limitação ou inibição da retração de poros devido ao aprisionamento de gás no interior dos poros isolados; e ii) expansão dos poros devido ao aumento da pressão de gás no interior dos poros isolados. Todos os fatores mencionados influenciam o comportamento de densificação, principalmente quando a sinterização é realizada acima da temperatura necessária para atingir máxima densidade, pois as duas porcelanas exibiram coalescimento e/ou crescimento de poros em elevadas temperaturas, conforme observado na Fig. 6a e na literatura $[2,3]$.

As transmitâncias específicas das porcelanas sem pigmentação e com adição de $0,5 \%$ de $\mathrm{CuO}$ sinterizadas entre 1200 e $1270^{\circ} \mathrm{C}$ são mostradas na Fig. 10. Após sinterização a $1200{ }^{\circ} \mathrm{C}$, condição em que se atingiu máxima DA (Fig. 6a), a porcelana sem pigmentação exibiu transmitância específica (Te) ao redor de $57 \% / \mathrm{mm}$ para a luz vermelha $(\lambda=624 \mathrm{~nm})$, mas valores baixos de Te, próximos de $20 \% / \mathrm{mm}$, foram obtidos para as luzes verde $(\lambda=525 \mathrm{~nm})$ e amarela $(\lambda=590 \mathrm{~nm}$, Fig. 10a). Os valores de Te da porcelana sem pigmentação variaram com o aumento da temperatura de sinterização de 1200 para $1250{ }^{\circ} \mathrm{C}$. Nesta faixa de temperatura, os valores de Te para luz vermelha foram abaixo $(41-47 \% / \mathrm{mm})$ daquele obtido a $1200{ }^{\circ} \mathrm{C}(57 \% / \mathrm{mm})$, sendo Te maximizado a 1230 ${ }^{\circ} \mathrm{C}$ para a luz verde $(\sim 32 \% / \mathrm{mm})$ e $1210{ }^{\circ} \mathrm{C}$ para a luz amarela $(\sim 30 \% / \mathrm{mm})$. Porém, a melhor condição de translucidez foi obtida após sinterização a $1270{ }^{\circ} \mathrm{C}$ (Fig. 10a), cujos valores máximos de Te foram de $\sim 76 \% / \mathrm{mm}$ para a luz vermelha, $\sim 44 \% / \mathrm{mm}$ para a luz verde e $\sim 30 \% / \mathrm{mm}$ para a luz amarela. A adição de $0,5 \%$ de $\mathrm{CuO}$ diminuiu o valor de Te, referente à luz vermelha, de $\sim 57 \% / \mathrm{mm}$ para $~ 19 \% / \mathrm{mm}$ (redução equivalente a 66,7\%) após sinterização a $1200{ }^{\circ} \mathrm{C}$ (Fig. 10b). Em relação às luzes verde e amarela, a redução foi de $100 \%$ na sinterização a $1200{ }^{\circ} \mathrm{C}$, pois a porcelana com
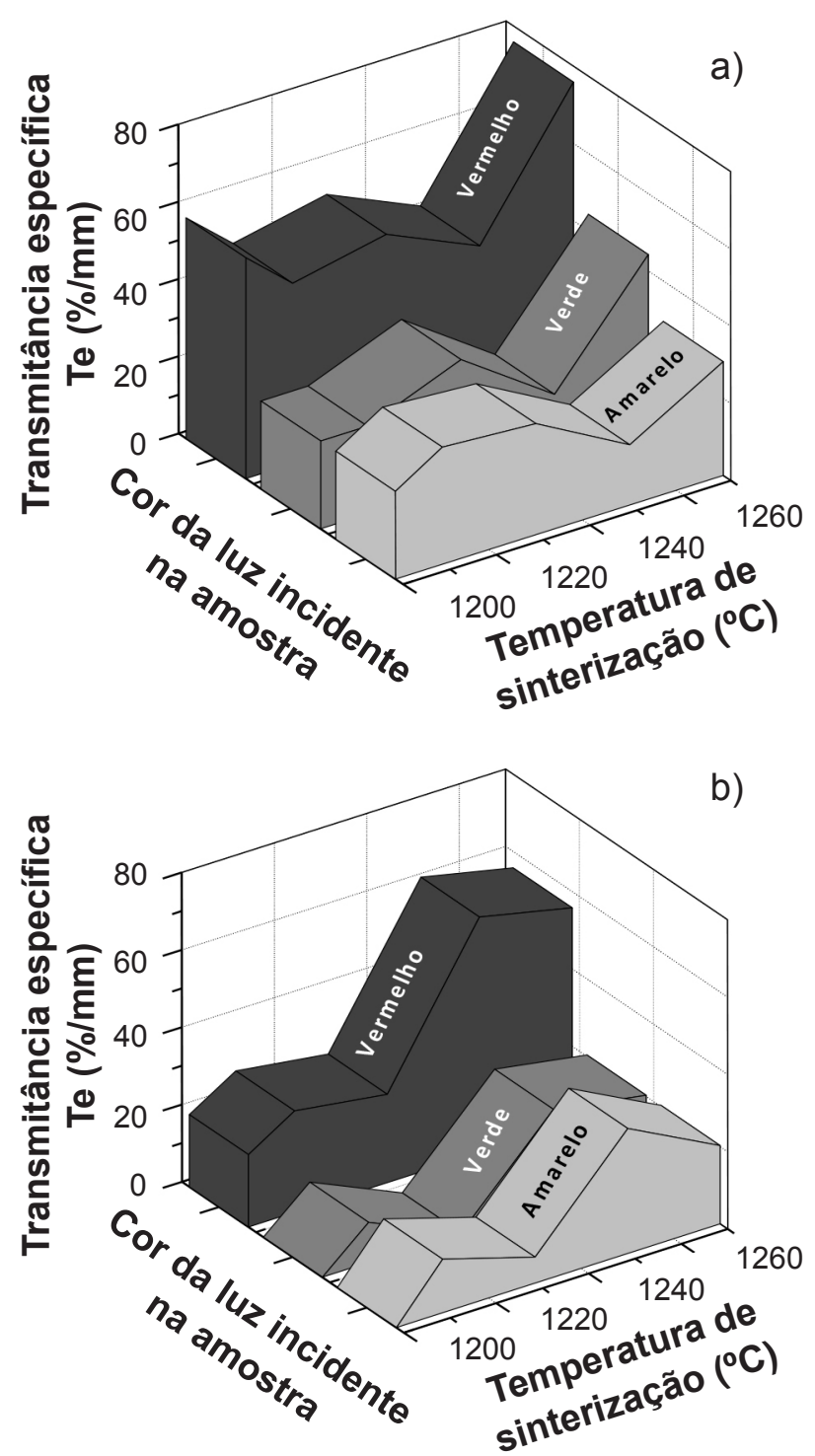

Figura 10: Transmitância específica (Te) em função da temperatura de sinterização para as porcelanas sem pigmentação (a) e com adição de $0,5 \%$ em massa de $\mathrm{CuO}$ (b).

[Figure 10: Specific transmittance (Te) as a function of the sintering temperature for porcelains without pigmentation (a) and with addition of $0.5 \mathrm{wt} \% \mathrm{CuO}(\mathrm{b})$.] 


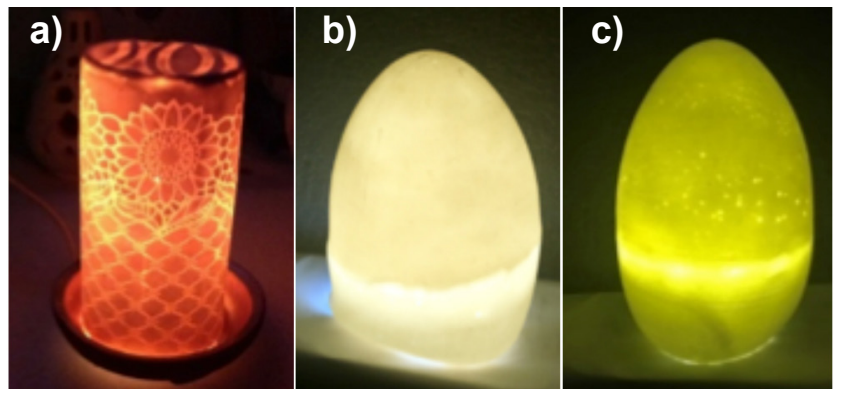

Figura 11: Protótipos de luminárias para decoração de ambientes (iluminados com luz branca): (a) porcelana sem pigmentação com parede espessa; (b) porcelana sem pigmentação com parede fina; e (c) porcelana com $0,5 \%$ de $\mathrm{CuO}$ de parede fina.

[Figure 11: Prototypes of decorative lighting fixtures (illuminated with white light): (a) porcelain without pigmentation with thick wall; (b) porcelain without pigmentation with thin wall; and (c) porcelain with $0.5 \% \mathrm{CuO}$ with thin wall.]

$0,5 \%$ de $\mathrm{CuO}$ exibiu $\mathrm{Te}=0$ para os referidos comprimentos de onda. Valores otimizados de Te foram obtidos para a porcelana com $0,5 \%$ de $\mathrm{CuO}$ após sinterização a $1250{ }^{\circ} \mathrm{C}$ (Fig. 10b), sendo obtidos valores de $\sim 61 \% / \mathrm{mm}$ para a luz vermelha, $\sim 24 \% / \mathrm{mm}$ para a luz verde e $\sim 32 \% / \mathrm{mm}$ para a luz amarela. Comparando-se estes resultados com os valores otimizados de Te para a porcelana sem pigmentação (1270 ${ }^{\circ} \mathrm{C}$, Fig. 10a), a diminuição de Te devido à adição de $0,5 \%$ de $\mathrm{CuO}$ correspondeu a $18,7 \%$ para a luz vermelha e $45,4 \%$ para a luz verde. Porém, Te teve um ganho de $10 \%$ para a luz amarela, mantendo-se a mesma comparação entre as referidas condições experimentais. Além disso, a porcelana com $0,5 \%$ de $\mathrm{CuO}$ sinterizada a $1270{ }^{\circ} \mathrm{C}$ apresentou valores de Te próximos daqueles obtidos para a porcelana sem pigmentação sinterizada a $1200{ }^{\circ} \mathrm{C}$ (Fig. 10).

Poros afetam as propriedades ópticas dos materiais [11], pois podem causar [10]: i) refração da luz emergente devido às diferenças dos índices de refração entre a fase vítrea e o ar (espaço vazio - poro); e ii) reflexão da luz emergente na superfície interfacial entre a fase vítrea e o poro. Porém, a maximização da transmitância ocorreu quando as duas porcelanas exibiram significativo crescimento e coalescimento de poros (Fig. 7), ou seja, quando as porcelanas foram sinterizadas em temperaturas superiores àquelas necessárias para atingir máxima DA(Fig. 6a). Apesar dos poros terem um efeito deletério sobre as propriedades ópticas, a presença de poros não pode ser considerada como o principal fator que influenciou a translucidez das porcelanas sem pigmentação e com adição de $0,5 \%$ de $\mathrm{CuO}$. Peças com paredes espessas e superfícies rugosas causam maior difusão ou absorção da luz emergente, diminuindo a quantidade de luz que transpassa o produto cerâmico. A Fig. 11 mostra imagens de alguns protótipos de luminárias produzidos com as porcelanas sem pigmentação e com adição de $0,5 \%$ de $\mathrm{CuO}$. A luminária com parede espessa e detalhes superficiais (Fig. 11a) teve maior difusão da luz emergente do que as luminárias produzidas com parede fina e sem detalhes superficiais (Figs. 11b e 11c). Outro fator que influencia a translucidez é a formação de fases cristalinas, que levam à formação de contornos de grão que podem causar tanto reflexão como refração da luz emergente $[10,11]$. Este fator foi minimizado com o aumento da temperatura, pois as partículas de $\mathrm{SiO}_{2}$ (Figs. 7d e 9b) não foram observadas nas matrizes vítreas das duas porcelanas sinterizadas acima de $1250{ }^{\circ} \mathrm{C}$. Assim, a ausência destas partículas é um indicativo que o aumento de temperatura causou a dissolução tanto das partículas supracitadas como de eventuais residuais de fases cristalinas na matriz vítrea. A porcelana sem pigmentação teve máxima transmitância após sinterização a $1270{ }^{\circ} \mathrm{C}$ (Fig. 10a), mostrando que a dissolução de partículas ou fases cristalinas na matriz vítrea resultou em maior translucidez, mesmo com a ocorrência de crescimento e coalescimento de poros (Figs. 7a, 7b e 8a). Portanto, o efeito deletério do crescimento de poros na transmitância não sobrepujou o efeito benéfico da dissolução de partículas ou fases cristalinas na matriz vítrea, visto que a translucidez aumenta devido à formação de uma matriz vítrea homogênea [10].

Apesar da presença de partículas de $\mathrm{SiO}_{2}$ na porcelana com $0,5 \%$ de $\mathrm{CuO}$ sinterizada a $1250{ }^{\circ} \mathrm{C}$ (Figs. $7 \mathrm{~d}$ e 9b), a adição deste pigmento levou à formação de uma matriz vítrea mais homogênea em relação à porcelana sem pigmentação, o que resultou em maior transmitância para a porcelana com $0,5 \%$ de $\mathrm{CuO}\left(1250{ }^{\circ} \mathrm{C}\right.$, Fig. 10). O aumento da temperatura de sinterização possibilitou a formação de uma matriz vítrea mais homogênea, mas este procedimento causou a diminuição da transmitância da porcelana com $0,5 \%$ de $\mathrm{CuO}$ (1250 para $1270{ }^{\circ} \mathrm{C}$, Fig. 10b). Neste caso, o efeito deletério do crescimento de poros foi dominante em relação ao efeito benéfico da dissolução de partículas ou fases cristalinas na matriz vítrea. Em suma, o aumento da temperatura de sinterização, acima da necessária para atingir máxima DA, promoveu o aumento de transmitância, independentemente da adição ou não de pigmento (corante). Por outro lado, o uso de elevada temperatura de sinterização aumenta significativamente a fração de fase líquida presente durante a sinterização, o que causa distorções na forma geométrica do produto cerâmico [2]. As luminárias de parede fina produzidas com as porcelanas sem pigmentação (Fig. 11b) e com 0,5\% de $\mathrm{CuO}$ (Fig. 11c) exibiram problemas de distorção geométrica após sinterização em elevadas temperaturas. Em relação ao efeito decorativo da porcelana colorida e translúcida, verificou-se que a adição de pigmento $(0,5 \%$ em massa de $\mathrm{CuO})$ proporcionou um efeito diferenciado, pois modificou sensivelmente a cor da luz (de branco para verde) emitida pela luminária (Fig. 11).

\section{CONCLUSÕES}

Protótipos de luminária para decoração de ambiente foram produzidos com porcelanas coloridas e translúcidas. A formulação cerâmica otimizada exibiu os constituintes tradicionais de uma massa triaxial (43\% de caulim, $17 \%$ de quartzo e $36 \%$ de feldspato), além da adição de $1 \%$ de bentonita e $3 \%$ de wollastonita (\% em massa). O óxido de cobre preto $(\mathrm{CuO})$ foi usado como pigmento (corante) para colorir a massa cerâmica usada na produção da porcelana 
translúcida. $\mathrm{O}$ teor otimizado de $\mathrm{CuO}$ foi de $0,5 \%$ em massa, que resultou em uma porcelana translúcida de cor verde claro após sinterização ao ar na temperatura de $1250{ }^{\circ} \mathrm{C}$ por $1 \mathrm{~h}$. A porcelana colorida e translúcida propiciou um efeito decorativo diferenciado em relação à porcelana translúcida tradicional sem adição de corantes (pigmentos).

\section{AGRADECIMENTOS}

Os autores agradecem à colaboração do Laboratório de Caracterização Tecnológica (LCT) do Departamento de Minas e Petróleo da Universidade de São Paulo (USP) pelos ensaios de microscopia eletrônica de varredura e microanálise química por energia dispersiva.

\section{REFERÊNCIAS}

[1] W.M. Carty, U. Senapati, J. Am. Ceram. Soc. 81, 1 (1998) 3.

[2] C. Zanelli, M. Raimondo, G. Guarini, M. Dondi, J. NonCryst. Solids 357 (2011) 3251.

[3] Y. Zhang, Y. Yang, W. Li, Y. Ren, Int. J. Appl. Ceram. Technol. 12, 4 (2015) 875.

[4] G.N. Maslennikova, T.I. Koneshova, Glass Ceram. 44, 4 (1987) 152.

[5] A. Capoglu, J. Eur. Ceram. Soc. 31 (2011) 321.

[6] C.B. Ustundag, Y.K. Tur, A. Capoglu, J. Eur. Ceram. Soc. 26 (2006) 169.

[7] B.I. Bondarenko, L.S. Blokh, Glass Ceram. 36, 8 (1979) 444.
[8] L.S. Blokh, B.I. Bondarenko, V.K. Bezuglyi, Glass Ceram. 38, 5 (1981) 240.

[9] S.R. Bragança, C.P. Bergmann, Cerâmica 50, 316 (2004) 291.

[10] Y.J. Liu, X.F. Wang, J.F. Huang, J. Liu, Q.G. Wang, Adv. Mater. Res. 311-313 (2011) 2157.

[11] D.W. Richerson, Modern ceramic engineering: properties, processing, and use in design, $2^{\text {nd }} E d$., CRC Press Taylor \& Francis, USA (2006) 356.

[12] A.B. Jermolovicius, G. Henrique, W.C. Gomes, "Desenvolvimento de porcelana translúcida colorida", Trabalho Conclusão Curso, Técnico em Cerâmica, Escola SENAI Mario Amato, S. Bernardo Campo (2013).

[13] Am. Soc. Test. Mater., ASTM C 373-88: "Standard test method for water absorption, bulk density, apparent porosity, and apparent specific gravity of fired whiteware products" (2006).

[14] D.C. Harris, Quantitative chemical analysis, $7^{\text {nd }}$ Ed., W.H. Freeman, USA (2007) 378.

[15] Y. Iqbal, W.E. Lee, J. Am. Ceram. Soc. 83, 12 (2000) 3121.

[16] M.S. Conconi, M.R. Ganna, M.F. Serra, G. Suarez, E.F. Aglietti, N.M. Rendtorff, Cerâmica 60 (2014) 524.

[17] M. Chen, B. Zhao, J. Am. Ceram. Soc. 96, 11 (2013) 3631.

[18] N. Hellstén, P. Taskinen, Calphad 59 (2017) 182.

[19] Q. Xiao, H. Ma, X. Zhao, J. Am. Ceram. Soc. 91, 1 (2008) 252.

(Rec. 16/09/2017, Rev. 29/11/2017, 04/01/2018, Ac. $11 / 01 / 2018)$ 